Marquette University

e-Publications@Marquette

College of Nursing Faculty Research and

Publications

Nursing, College of

6-1-2012

\title{
Mental Health of Elders in Retirement Communities: Is Loneliness a Key Factor?
}

Abir K. Bekhet

Marquette University, abir.bekhet@marquette.edu

Jaclene Zauszniewski

Case Western Reserve University

Accepted version. Archives of Psychiatric Nursing, Vol. 26, No. 3 (June, 2012): 214-224. DOI. (C) 2012 Elsevier. Used with permission. 


\title{
Mental health of elders in retirement communities: Is loneliness a key factor?
}

\author{
Abir K Bekhet, PhD, RN, H.S.M.I.[Assistant Professor] and \\ Marquette University College of Nursing, Clark Hall, 530 N. 16th Street, Milwaukee, WI 53233 \\ Jaclene A. Zauszniewski, Ph.D., RN-BC, FAAN \\ Kate Hanna Harvey Professor in Community Health Nursing, Professor and Associate Dean for \\ Doctoral Education, Frances Payne Bolton School of Nursing, Case Western Reserve University, \\ 10900 Euclid Avenue, Cleveland, Ohio 44106-4904, Phone: 216-368-3612, FAX: 216-368-3542
}

\section{Mental health of elders in retirement communities: Is loneliness a key factor?}

In the U.S., the population of older adults is increasing rapidly; their numbers are expected to reach 71 million by 2030 (Centers for Disease Control and Prevention [CDC], 2007). Chronic illnesses increase with age (Rice \& Fineman, 2004); 80\% of American elders have at least one chronic condition and 50\% have two or more (CDC, 2003). Chronic conditions decrease elders' independence and functioning and interfere with their daily activities (Merck Institute of Aging \& Health (MIAH), CDC, \& Gerontological Society of America (GSA), 2004; National Center for Health Statistics, 1999). As a result, the number of elders living in retirement communities is increasing. Statistics have shown, however that relocated elders report feelings of loneliness, depression, anxiety, and stress (Hodgson, Freedman, Granger, \& Emo, 2004; Lutgendorf et al., 2001).

Research has shown that many older adults suffer from loneliness (Ekwall, Sivberg, Hallberg, 2005; Eshbaugh, 2009). Often described as an "emptiness" or "hollow feeling" (Dong et al., 2007; Austin, 1989), loneliness can threaten one's feelings of personal worth and decrease confidence in the ability to develop and maintain interpersonal relationships (Alpass \& Neville, 2003). Loneliness has been described as a pervasive, depressing, debilitating condition that may adversely affect one's quality of life (Bekhet, Zauszniewski, \& Nakhla, 2008; Killeen, 1998); it is often manifested by intense feelings of emptiness and abandonment (Dong et al., 2007).

In fact, the definition of loneliness can fall under one of three categories. The first category is a state-related form of loneliness, which could be influenced by situational and social factors such as relocation, changes in health, functional capacity, and social network and can be described as transient and reactive (Mayers \& Svartberg, 2001; Tiikkainen \& Heikkinen, 2005). The second category is a trait or personality-related form of loneliness that could arise, for example, from maternal problems of early childhood attachment. Each of these

(C) 2011 Elsevier Inc. All rights reserved.

Corresponding author: Abir K Bekhet, PhD, RN, H.S.M.I., Marquette University College of Nursing, 530 N. 16th Street, Milwaukee, WI 53233, Phone: 414-288-3847, abir.bekhet@marquette.edu.

Publisher's Disclaimer: This is a PDF file of an unedited manuscript that has been accepted for publication. As a service to our customers we are providing this early version of the manuscript. The manuscript will undergo copyediting, typesetting, and review of the resulting proof before it is published in its final citable form. Please note that during the production process errors may be discovered which could affect the content, and all legal disclaimers that apply to the journal pertain. 
categories of loneliness can be treated with different interventions (Mayers \& Svartberg, 2001). The third category views loneliness as an inevitable condition of existence with a basic sense of existential loneliness; relief from this feeling can never be complete (Mayers $\&$ Svartberg, 2001; Mijuskovic, 1977). Although these three categories of definitions of the concept of loneliness have not been referenced specifically in nursing literature, it is likely that they may be applicable.

In the nursing literature, loneliness has been described primarily in terms of its negative characteristics (Rosedale, 2007). It has been viewed narrowly as a symptom of health dysfunction that is related to a lack of social support and general well being and associated with certain age groups, such as adolescents and older adults (Mahon et al., 1994; Mclnnis \& White, 2001; Rosedale, 2007). However, scholars from other disciplines have identified both negative and positive aspects of loneliness. For example, philosophers view loneliness as a vital element of human existence and as a motivating force for achieving a new connection, truth, and meaning and for discovering new possibilities (Rosedale, 2007). Although psychological scholars differ on whether loneliness is unidimensional or multidimensional, they agree that loneliness is an experience of separation that is associated with dissatisfaction and emotional distress and might arise during childhood and continue throughout life. Like philosophers, psychological scholars view loneliness as a motivational force for finding meaning, developing connections, and realizing one's fullest potential (Rosedale, 2007). Thus, the interpretation of the meaning of loneliness can be very subjective and it can differ from one elder to the next.

The prevalence of loneliness in older adults is estimated to be $40 \%$, and this figure has been relatively constant over the last 25 years (Cohen-Mansfield \& Parpura-Gill, 2007). A number of factors have been identified as contributing to loneliness. Among these are selfassessed poor health status (Creecy, Berg, \& Wright,1985; Mullins et al.,1996; Alpass \& Neville, 2003), physical limitations (McWhirter, 1990), chronic illnesses (Alpass \& Neville, 2003; Russell, 1996), and physical or mental decline (Fokkema \& Knipscheer, 2007).

Research has shown that there was a positive associations between loneliness and suicide (McWhirter, 1990) and loneliness and depression (Dong et al., 2007; Russell, 1996). In addition, feelings of loneliness may exacerbate the physiological effects of stress, resulting in elevated cortisol (Hawkley, Burleson, Berntson, \& Cacioppo, 2003; Steptoe, Owen, Kunz-Ebrecht, \& Brydon, 2004) and blood pressure (Hawkley, et al 2003; Cornwell \& Waite, 2009).

\section{Theoretical framework}

The loneliness theoretical framework proposed by Hawkley and Cacioppo (2010) was used to provide the context for analyzing available data within this secondary analysis. Hawkley and Cacioppo's model of loneliness addresses the mechanism and the consequences of loneliness (figure 1). According to this model, loneliness has physical and mental consequences. While physical consequences of loneliness may include lower self-rated health, greater functional limitations, more chronic diseases and diminished functional status, mental consequences may include increased depressive symptoms and anxiety (Hawkley \& Cacioppo, 2010). The theory also addresses mechanisms of loneliness and proposes that a diminished capacity of self regulation (conceptualized as resourcefulness in this study) has an impact on the consequences of loneliness (Figure 1).

This secondary analysis examined differences between elders reporting and not reporting loneliness and the effect of gender on a potential mechanism (resourcefulness), a general measure of health consequences that captures both physical and mental health, and more specific measures of possible mental and physical health consequence of loneliness as 
articulated in the theoretical model by Hawkley and Cacioppo (2010) described above. In this analysis, loneliness was measured with a single item that asked the elders whether they felt lonely or not. No definition was provided for the concept of loneliness in the original study. According to Rosedale, definitions of loneliness are highly subjective (Rosedale, 2007).

Self-assessed health was used as an indicator of overall health. Physical health consequences included number of chronic conditions and functional status. Mental health consequences included anxiety and depressive symptoms (Figure 1). The following research questions were addressed in this study:

1. Do elders who report feeling lonely differ from those who do not report feeling lonely on resourcefulness, a proposed mechanism associated with loneliness?

2. Do elders who report feeling lonely differ from those who do not report feeling lonely on their perception of overall health?

3. Do elders who report feeling lonely differ from those who do not report feeling lonely on physical health consequences (greater number of chronic conditions and impaired functional status)?

4. Do elders who report feeling lonely differ from those who do not report feeling lonely on mental health consequences (anxiety and depressive symptoms)?

5. Do elderly men differ from women on a mechanism (resourcefulness) and physical and mental health consequences believed to be associated with loneliness?

Data used in this study were collected from 314 older adults who were recruited from 29 retirement communities, which have been published elsewhere (Zauszniewski, Morris, Preechawong, \& Chang, 2004). Approval from the Institutional Review Board was obtained prior to recruiting the elderly study participants for the parent study, from whom informed consent was obtained prior to data collection during face-to-face interviews with trained data collectors in a private setting within the retirement community (RC) in which they lived.

\section{Methods}

\section{Design and Sample}

A descriptive and comparative design was used to examine gender differences and associations between loneliness and indicators of physical and mental health consequences and resourcefulness skills in older adults who resided in RCs in Northeast Ohio. RCs included assisted living facilities and independent living facilities that provided services and assistance with daily activities to older adults. A sample of 314 residents, 250 women and 64 men, who were willing to participate in the parent study was recruited from $29 \mathrm{RCs}$ (Zauszniewski, et al, 2004). To be included, residents had to be able to read, understand, and speak English; receive services or assistance with at least one of the basic or instrumental activities of daily living, including ambulation, toileting, meal preparation, shopping, and housework; and be cognitively intact, as determined by a score of 7 or higher on the 10-item Short Portable Mental Status Questionnaire (SPMSQ) (Pfeiffer, 1975).

Pertinent results from the parent study indicate that the most commonly reported negative emotions in the 314 elders were sadness (29.0\%), loneliness (28.7\%), nervousness (26.4\%), worry (24.5\%), and anxiousness (23.9\%). Of the 64 men in the sample, loneliness was reported most frequently $(25.0 \%)$ followed by irritability (21.9\%). Of the 250 women in the sample, sadness was reported most frequently $(31.2 \%)$ followed by loneliness $(29.6 \%)$. Cohort analysis showed that the young-old (ages 65 through 74) and middle-old (ages 75 through 84 ) adults reported sadness most frequently (25.6\% and 33.3\%, respectively); the 
middle-old also reported nervousness (33.3\%). The old-old age cohort (ages 85 and older) reported loneliness $(30.8 \%)$ most frequently.

For the analysis reported here, the sample size of 314 elders, including 250 women and 64 men, was sufficient for determining associations between loneliness and gender in relation to resourcefulness and physical and mental health indicators with an minimum effect size of .32, power of .80, and significance level of .05 (Bausell \& Li, 2002).

\section{Instruments}

Demographic information collected included age, recorded as the participant's reported age in years and birth date, gender and race, recorded based on participant self-report.

Loneliness was measured by a single item that asked the study participants whether they felt lonely or not. As described previously, the elders' response to this item was left to their interpretation; no definition of loneliness was suggested to them.

\section{Mechanism affected by loneliness}

Resourcefulness was measured by the Self-Control Schedule (SCS) (Rosenbaum, 1980), which consists of 36 Likert-type items responded to using a 6-point scale. Participants indicate the degree to which each item describes their behavior, ranging from not at all like me (0) to very much like me (5). Scores range from 0 to 180; higher composite score, after reverse scoring for 11 items negatively phrased, indicate greater resourcefulness. Acceptable psychometric properties of the scale have been documented. Internal consistency estimates ranging from .72 to .83 have been reported in studies with older adults with chronic conditions (Bekhet, Zauszniewski, \& Wykle, 2008; Potter \& Zauszniewski, 2000; Zauszniewski, Eggenschwiler, Preechawong, Roberts, \& Morris, 2006). Cronbach's alpha in this sample was .72. Construct validity has been demonstrated by significant correlations between the SCS measure of resourcefulness and greater spirituality (Potter \& Zauszniewski, 2000), lower anxiety and depression (Zauszniewski et al., 2006), more positive cognitions and greater control related to relocation (Bekhet et al., 2008).

The SCS was designed to tap four theoretical dimensions: positive self-instructions, problem solving, delay of gratification, and perceived self-efficacy (Rosenbaum, 1980). Rosenbaum re-conceptualized these components into three dimensions: redressive self-control, reformative self-control, and perceived self-efficacy (Rosenbaum, 1990). Previous factor analytic studies have supported that the SCS items loaded similarly on three factors, consistent with Rosenbaum's (1990) dimensions of learned resourcefulness (Gruber \& Wildman, 1987; Zauszniewski, 1995). Rosenbaum (1990) stated that 12 items of the SCS referred to the use of cognitions to control emotional and physiological sensations (redressive self-control), 15 items referred to the tendency to employ problem-solving strategies and delay immediate gratification (reformative self-control), and 9 items were indicative of general expectations of self-efficacy (belief in one's capacity to cope with the problem).

\section{Measure of overall health (physical and mental) consequence}

Self-Assessed Health was used to capture overall health, including both physical and mental health. It was measured by three items that asked participants to rate their physical health as excellent $=4$, good $=3$, fair $=2$, or poor $=1$; to rate their health in comparison to their peers as worse $=1$, the same $=2$, or better $=3$; and to rate the extent to which their health interfered with daily activities as not at all $=1$, some interference $=2$, or extremely bothersome $=3$. Individual scores were standardized and then summed for an overall total score; higher scores indicated better self-assessed health. Subjective measures of perceived 
health status have been widely used in studies of older adults, and many studies indicate that self-rated health is a reliable and valid substitute for objective measures (Amstadter, Begle, Cisler, Hernandez, Muzzy, \& Acierno, 2010). Cronbach's alpha for the three item measure in this sample was .54 .

\section{Measures of physical health consequences}

Number of chronic conditions were measured using a questionnaire developed by Fillenbaum (1988) to assess the presence of chronic conditions (26 different disorders). The instrument provides a checklist for respondents to indicate whether or not they experience such conditions as arthritis, hypertension, diabetes, heart disease, and 22 other conditions. This is the same measure as used in the physical health component of the Older Adults Resources and Services (OARS) Multidimensional Functional Assessment Questionnaire (MFAQ) (Fillenbaum, 1988). This well-known measure has widely reported reliability and validity in over 500 studies of elders (Bruce \& Fries, 2003). Cronbach's alpha for this sample was .86 (Zauszniewski, et al, 2004).

Functional status was measured by the Health Assessment Questionnaire (HAQ) (Fries, 1996), which includes 20 questions on the functioning of respondents during the past week. Functioning is assessed in eight areas: dressing and grooming, arising, eating, walking, hygiene, reaching, gripping, and outdoor activities. Each component includes 2-3 questions. Responses are scored on a 4-point scale of ability ranging from "without any difficulty" to "unable to do." Scores for the eight components are added for a total score that ranges from 0 to 24. Lower scores indicate greater self-sufficiency in performing daily activities. This well known measure has reported reliability and validity from over 500 studies of older adults (Bruce \& Fries, 2003). Cronbach's alpha for this sample was .86.

\section{Measures of mental health consequences}

Anxiety was measured by the State Anxiety Inventory (STAI A-State), a 20-item scale that measures current anxiety (Spielberger, 1983). Participants rate the degree to which items describe current feelings on a 4-point Likert-type scale, ranging from not at all (0) to very much so (3). Scores range from 0 to 60 ; higher scores, after reverse scoring for 10 items, indicate greater anxiety. The STAI has been widely used with diverse populations, including the elderly and has been found reliable and valid in older adults, with Cronbach's alpha of . 94 and evidence of convergent validity with measures of fear, worry, and general anxiety (Stanley, Novy, Bourland, Beck, \& Averill, 2001). Cronbach's alpha for the STAI in this sample was .88 .

Depressive symptoms were measured by the Center for Epidemiological Studies Depression Scale (CES-D) and the short form of the CES-D. The 20-item CES-D (Radloff, 1977) asks participants to rate the frequency with which they experienced each listed symptom during the week prior to the interview on a 4-point Likert-type scale ranging from rarely or none of the time (0), to most or all of the time (3). Scores range from 0 to 60; higher scores after reverse coding for 4 items indicate greater frequency of depressive symptoms. The scale is a widely reported valid measure, and it has been standardized for a variety of ages and racial groups. Alpha coefficients of.84 for elderly women with chronic conditions (Zauszniewski, \& Bekhet, 2009), .87 for elders with diabetes (Zauszniewski \& Graham, 2009), and .85 for elders living in retirement communities have been reported (Zauszniewski, et al, 2004). Cronbach's alpha for this sample was .85 . 


\section{Results}

\section{Loneliness}

Among the total sample of elders ( $\mathrm{N}=314)$, nearly $29 \%(\mathrm{n}=91)$ reported feeling lonely. This percentage included 30\% ( $\mathrm{n}=75)$ of the women and $25 \%(\mathrm{n}=16)$ of the men. However, chi square analysis showed that the two groups did not significantly differ $\left(X^{2}=0.62, p=.43\right)$.

\section{Loneliness and resourcefulness}

To examine the effect on resourcefulness as a mechanism believed to be affected by loneliness (Hawkley \& Cacioppo, 2010), a 2 (male versus female gender) $\times 2$ (report of loneliness or not) between-subjects factorial analysis of variance (ANOVA) was conducted to compare resourcefulness scores from the elderly study participants. The overall model was significant $[F(3,310)=3.35, p<.02]$. A significant main effect was found for gender $[F(1,310)=4.37, p<.04]$ and the main effect of loneliness approached significance $[F(1,310)=3.02, p<.09)$. Female elders had higher mean scores on resourcefulness ( $n=250$; $m=129.41, s d=18.11)$ than male elders $(n=64 ; m=123.50, s d=20.66)$. Elders who reported not feeling lonely had higher resourcefulness scores $(n=223 ; m=129.62, s d=18.49)$ than those who reported feeling lonely ( $n=91 ; m=124.75, s d=19.12)$. The interaction of gender and loneliness was not significant. Means and standard deviations on resourcefulness for the total sample and the men and women elders appear in Table 1.

\section{Loneliness and perceived overall health}

To examine the effects of loneliness on physical health consequences as proposed by Hawkley and Cacioppo (2010), a 2 (male versus female gender) $\times 2$ (report of loneliness or not) between-subjects factorial analysis of variance (ANOVA) was conducted to compare self-assessed health scores from the elderly study participants. For this analysis, the overall model was not found to be significant, indicating that the elders' perception of their overall physical and mental health was neither influenced by their reported feelings of loneliness or their gender or the interaction of these two variables.

\section{Loneliness and physical health consequences}

To examine the effects of loneliness on physical health consequences as proposed by Hawkley and Cacioppo (2010), two 2 (male versus female gender) $\times 2$ (report of loneliness or not) between-subjects factorial ANOVAs were conducted to compare scores on number of chronic conditions and functional status from the elderly study participants. Similar to the measure of overall self-assessed health described above, for the number of chronic conditions, the overall model was not found to be significant. indicating that the elders' reported number of chronic conditions was neither influenced by their reported feelings of loneliness or their gender or the interaction of these two variables.

However, the analysis of functional status as a physical health consequence differed. The overall model for the analysis of the elders' functional status was significant $[F(3,310)=.35$, $p<.001]$. A significant main effect was found for gender $[F(1,310)=12.43, p<.001]$. Female elders had higher mean scores on functional status $(n=250 ; m=8.34, s d=5.03)$ than male elders ( $n=64 ; m=5.64, s d=3.79$ ), indicating that the women had greater functional impairment. The main effect of loneliness was not found to be significant and the interaction of gender and loneliness was also not significant. Means and standard deviations on functional status for the total sample and the men and women elders appear in Table 1. 


\section{Loneliness and mental health consequences}

To examine the effects of loneliness on mental health consequences as proposed by Hawkley and Cacioppo (2010), two 2 (male versus female gender) $\times 2$ (report of loneliness or not) between-subjects factorial ANOVAs were conducted to compare scores on anxiety and depressive symptoms from the elderly study participants. For the analysis of anxiety state, the overall model was significant $[F(3,310)=5.42, p<.001]$. A significant main effect was found for loneliness $[F(1,310)=10.61, p<.001]$. Elders who reported feeling lonely had higher anxiety scores $(n=91 ; m=8.04, s d=7.05)$ than those who reported not feeling lonely ( $n=223 ; m=5.08, s d=5.61$ ). The main effect of gender was not found to be significant and the interaction of gender and loneliness was not significant. Means and standard deviations on anxiety for the total sample and the men and women elders appear in Table 1.

For the analysis of depressive symptoms, the overall model was significant $[F(3,310)=8.97$, $p<.001]$. A significant main effect was found for loneliness $[F(1,310)=14.92, p<.001]$. Elders who reported feeling lonely had higher depressive symptom scores $(n=91 ; m=10.35$, $s d=7.71)$ than those who reported not feeling lonely ( $n=223 ; m=6.05, s d=6.17)$. The main effect of gender was not found to be significant and the interaction of gender and loneliness was not significant. Means and standard deviations on depressive symptoms for the total sample and the men and women elders appear in Table 1.

\section{Discussion}

In summary, we found that while elders' self-reported feelings of loneliness were strongly associated mental health consequences (anxiety and depressive symptoms), there was less of an association with resourcefulness (a potential mechanism), and no association with physical health indicators (number of chronic conditions and functional status). Gender was found to be associated with resourcefulness and physical function, though unrelated to the elders' report of loneliness. Interaction effects were not observed for any of the study variables.

Our study also found no significant differences between those who reported loneliness and those who reported no loneliness on overall health, functional status, or chronic conditions. Hawkley and colleagues (2008) also found no significant association between physical and functional health and loneliness in their sample of older adults. On the other hand, a study conducted by Cohen-Mansfield and Parpura-Gill (2007) found a positive correlation between mobility difficulties and loneliness $(r=.18, p<.01)$ in a sample of 161 residents of five independent living facilities. Dykstra and colleagues (2005), who examined loneliness and its correlates over seven years among older adults born between 1908 and 1937 found that respondents who reported declines in functional capacity showed an increase in loneliness and those who reported better functional capacity tended to be less lonely. However, it should be noted that their study was longitudinal while our study was cross sectional and thus it was impossible to assess changes in study variables over time. Longitudinal studies are needed that assess perceived health, functional status, and chronic conditions in relation to loneliness.

In our study, there were significant differences in anxiety between lonely and non-lonely elders in the total sample. Long and Martin (2000) also found that anxiety was related to loneliness $(B=.36, p<.001)$ among both oldest old parents and their children (Long \& Martin, 2000). Similarly, we found significant differences in depressive symptoms between lonely elders and non-lonely elders in the total sample. Similarly, Cohen-Mansfield and Parpura-Gill (2007) found a significant correlation between loneliness and depressed affect $(\mathrm{r}=.45, \mathrm{p}<.01)$ in their sample of residents of independent-living buildings for low income 
older adults in Maryland. Also, significant differences in resourcefulness were found between lonely elders and non-lonely elders in the total sample.

Our results indicated that differences between lonely elders and non lonely elders on resourcefulness approached significance. In the loneliness model proposed by Hawkley and Cacioppo (2010), a diminished capacity for self-regulation is described as a mechanism affected by loneliness. However, in the secondary analysis reported here, resourcefulness was examined as a potential mechanism in the absence of a measure of self-regulation. Yet, resourcefulness differs from self-regulation in that resourcefulness incorporates cognitivebehavioral skills that include both self-help (personal resourcefulness) and help-seeking (social resourcefulness) behaviors, which are important for promoting quality of life (Zauszniewski, 2006), while self-regulation is defined by Hawkley and Cacioppo (2010) in relation to an individual's thoughts, feelings, and behaviors associated with a specific health goal. Thus, while personal resourcefulness skills may incorporate self-regulation, the inclusion of social resourcefulness skills within the resourcefulness scale may have diminished the significance of the findings. Further research to examine the relationship between help-seeking (social resourcefulness) skills and loneliness is needed to determine the extent to which elders who feel lonely may or may not seek the help or assistance of others.

The use of convenience sampling in this study limits the generalizability of the findings for elderly persons and since the study was cross-sectional, it was impossible to assess changes in variables over time. A longitudinal study would be useful in examining causal effects among the study variables. Loneliness was measured by a single item that asked the study participants whether they felt lonely or not; the response restrictions (yes/no) of the loneliness instrument might affect the study findings. However, it might be an advantage to assess their loneliness by asking them a direct question whether they are lonely or not because the interpretation of the meaning of loneliness can be very subjective and it can differ from one elder to the next. Future qualitative studies that might ask older adults what they meant when they responded to the question in order to enhance the interpretation of such findings. Finally, given that data were collected during face-to-face interviews, social desirability may have influenced how the elderly persons responded to questionnaire items.

Despite these limitations, the findings from the current study suggest a need to develop intervention programs to prevent or reduce loneliness. The causes of loneliness are multidimensional and may include poor coping strategies, insecure attachments, failure expectations, and relationships that lack intimacy (Heinrich \& Gullone, 2006; Seapersad, 2010). In addition, the experience of loneliness may not reflect a personal deficit or specific limitation in the older adult so that capturing its meaning from the elderly person's perspective is essential before designing and implementing interventions. Thus, although a wide variety of intervention activities may be needed to deal with the different causes of loneliness, careful attention must be paid to the accurate, measurement of loneliness before initiating any intervention.

Three broad goals of loneliness intervention programs have been identified: to develop gratifying interpersonal relationships, prevent loneliness from developing in at-risk populations, and prevent loneliness from developing into more serious problems (De Vlaming, Haveman-Nies, Veer, \& De Groot, 2010; Rook, 1984). One intervention found to be effective in dealing with loneliness is cognitive therapy (Winningham \& Pike, 2007; Evans \& Dingus, 1989; Murphy \& Kupshik, 1992). Lonely persons may have distorted thinking, including expectations that they will be rejected in new social situations such as a retirement community. Research has shown that these individuals tend to acquire a pessimistic avoidance cognitive strategy (Nurmi, Toivonen, Salmela-Aro, \& Eronen, 1997). 
Thus, cognitive therapy may help older adults correct pessimistic beliefs by recognizing and modifying self-defeating thought patterns (Fava et al., 2004; Rook, 1984; Rush, \& Beck, 2000). This, in turn, will help decrease loneliness and improve their sense of belonging. Longitudinal studies would be useful in determining the effects of positive cognition interventions on loneliness among older adults.

Modifying interpersonal orientation is another possible intervention. With this intervention, older adults establish a relationship of trust with a nurse or health team that allows for selfdisclosure. Thus they learn to change their cognitions and behavior based on an actual relationship. In this sense, the nurse adopts the role of an attachment figure and the older adults adopt different expectations about unknown people, as a basis for better attempts at constructing personal relationships (Rook, 1984).

Teaching adaptive coping strategies is another intervention that has proven to be effective in reducing loneliness. Lonely individuals sometimes adopt coping strategies that increase their loneliness (Dong et al., 2007; Pavri, 2001; Rook, 1984). Intervention programs can teach lonely individuals how to effectively cope with their loneliness, including coping in ways that increase the possibility of social contact. It is important to teach older adults that loneliness is controllable and they can adopt more effective coping strategies (Ponzetti, 1990).

Among older adults who have relocated to retirement communities, a sense of belonging can be enhanced by providing elders help and guidance needed to find their way in the new community. Recently relocated older adults should be screened for loneliness. Individual counseling and/or group discussions can reduce worries, loneliness and stressors that older adults might have.

Loneliness in older adults may arise from feeling not really understood due to one's having outlived those persons who have a shared mutual history. It should be noted that there is a basic sense of existential loneliness. However, older adults can alleviate their feelings of loneliness although relief from this feeling can never be complete (Mayers \& Svartberg, 2001; Mijuskovic, 1977). Living alone in later life does not always resulting in feelings of loneliness (Cacioppo, Hughes, Waite, Hawkley, \& Thisted, 2006). Many researchers suggested that the quality rather than the quantity of the relationship that predict loneliness (Cacioppo et al., 2006; Pinquart \& Sorensen, 2003). Mental health nurses can offer psychological support by initiating short and frequent visit with older adults to show a feeling of interest and concern and alleviate their feelings of loneliness (Odell, 1981). Odell suggested that the nurse should assume a "person" role rather than a "nurse" role (Odell, 1981).

The nursing literature on loneliness views the concept of loneliness in a narrow way as related to pathological or deficit state (Rosedale, 2007). According to Rosedale (2007), there is a lack of clarity in theoretical frameworks, limiting frameworks to clinical or pathological antecedents, mediating processes, and outcomes, and failure to gain a deep understanding of the existential implications in the loneliness experience. According to Rosedale, definitions of loneliness are highly subjective and future investigations of this important concept can examine further. In fact, further qualitative investigations on the meaning of the concept of loneliness to individuals residing in retirement communities are needed and might be helpful in providing directions for future interventions. Further qualitative work regarding the cultural differences on the meaning of loneliness is also needed. Furthermore, future research should consider linking loneliness with more positive variables such as spiritual well-being and positive health practices (Mahon et al., 1994; Rosedale, 2007). In the parent study, it is possible that the low depression and anxiety scores were due to participants 
receiving treatment. Therefore, future research might consider asking older adults regarding whether they receive mood altering medications and control for its effects statistically.

In fact, mental health nurses are in a strategic role to explore the phenomenon of loneliness and to explore possible avenues for optimizing personal growth and minimizing isolation and negative consequences among older adults (Rosedale, 2007). This can be achieved by helping older adults through listening to their needs, learning about their expectations and their current relationships to identify and or to improve their existing relationships and helping them to develop new ones (Stevens, 2001)

\section{Acknowledgments}

Funding for the study was provided by National Institute of Nursing Research, National Institute of Health, Grant No. R01-NR-04428 awarded to Dr. Jaclene A. Zauszniewski (Principal Investigator; Musil, C.M., \& Roberts, B.L., Co-investigators; Morris, D.L., Consultant) for her study of " Teaching Resourcefulness to Chronically Ill Older Adults".

The authors acknowledge the editorial assistance of Elizabeth M. Tornquist of the University of North Carolina at Chapel Hill.

\section{References}

Alpass F, Neville S. Loneliness, health and depression in older males. Aging \& Mental Health. 2003; 7(3):212-216. [PubMed: 12775403]

Amstadter A, Begle A, Cisler J, Hernandez M, Muzzy W, Acierno R. Prevalence and correlates of poor self-rated health in the United States: the national elder mistreatment study. American Journal of Geriatric Psychiatry. 2010; 18(7):615-623. [PubMed: 20220579]

Austin AG. Becoming immune to loneliness: Helping the elderly fill a void. Journal of Gerontological Nursing. 1989; 15(9):25-30. [PubMed: 2778274]

Bausell, RB.; Li, YF. Power analysis for experimental research: A practical guide for the biological, medical, and social sciences. Cambridge University Press; United Kingdom: 2002. p. 239-301.

Bekhet A, Zauszniewski JA, Nakhla W. Loneliness: A Concept Analysis. Nursing Forum. 2008; 43(4): 207-213. [PubMed: 19076464]

Bekhet A, Zauszniewski JA, Wykle M. Midwest Nursing Research Society Sage Best Paper Award: Milieu Change and Relocation Adjustment in Elders. Western Journal of Nursing Research. 2008; 30(1):113-129. [PubMed: 18029543]

Bruce M, Fries J. The Stanford Health Assessment Questionnaire: A review of its history, issues, progress, and documentation. The Journal of Rheumatology. 2003; 30(1):167-178. [PubMed: 12508408]

Cacioppo JT, Hughes ME, Waite LJ, Hawkley LC, Thisted RA. Loneliness as a specific risk factor for depressive symptoms: Cross-sectional and longitudinal analyses. Psychology and Aging. 2006; 21(1):140-151. [PubMed: 16594799]

Center for Disease Control and Prevention. U.S. Department of Health and Human Services (USDHHS). The State of Aging and Health in America 2007 report. 2007. Available at http://www.cdc.gov/aging/saha.htm. Retrieved May 10, 2007

Centers for Disease Control and Prevention. Public health and aging United States and worldwide. Morbidity and Mortality Weekly Report. 2003; 52(6):101-106. [PubMed: 12645839]

Cohen-Mansfield J, Parpura-Gill A. Loneliness in older persons: A theoretical model and empirical findings. International Psychogeriatrics. 2007; 19(2):279-294. [PubMed: 17005067]

Cornwell EY, Waite LJ. Measuring social isolation among older adults using multiple indicators from the NSHAP study. The Journals of Gerontology Series B, Psychological Sciences and Social Sciences. 2009; 64(Suppl 1):i38-46.

Creecy RF, Berg WE, Wright R Jr. Loneliness among the elderly: A causal approach. Journal of Gerontology. 1985; 40:487-793. [PubMed: 4008883] 
De Vlaming R, Haveman-Nies A, Veer PV, De Groot LC. Evaluation design for a complex intervention program targeting loneliness in non-institutionalized elderly Dutch people. BMC Public Health. 2010; 10:552. [PubMed: 20836840]

Dong X, Simon M, Gorbien M, Percak J, Golden R. Loneliness in older Chinese adults: a risk factor for elder mistreatment. Journal of the American Geriatrics Society. 2007; 55(11):1831-1835. [PubMed: 17944895]

Dykstra P, van Tilburg T, Gierveld J. Changes in older adult loneliness: results from a seven-year longitudinal study. Research on Aging. 2005; 27(6):725-747.

Ekwall A, Sivberg B, Hallberg I. Loneliness as a predictor of quality of life among older caregivers. Journal of Advanced Nursing. 2005; 49(1):23-32. [PubMed: 15610378]

Eshbaugh E. The role of friends in predicting loneliness among older women living alone. Journal of Gerontological Nursing. 2009; 35(5):13-16. [PubMed: 19476188]

Evans, RL.; Dingus, CM. Serving the vulnerable: Models for treatment of loneliness. In: Hojat, M.; Crandall, R., editors. Loneliness: Theory, research and applications. Sage Publications; Newbury Park, CA: 1989. p. 249-256.

Fava GA, Ruini C, Rafanelli C, Finos L, Conti S, Grandi S. Six-year Outcome of Cognitive behavior therapy for prevention of recurrent depression. American Journal of Psychiatry. 2004; 161(10): 1872-1876. [PubMed: 15465985]

Fillenbaum, GG. Multidimensional functional assessment of older adults: The Duke Older Americans Resources and Services Procedures. Erbaum; Hillsdale, NJ: 1988.

Fokkema T, Knipscheer K. Escape loneliness by going digital: a quantitative and qualitative evaluation of a Dutch experiment in using ECT to overcome loneliness among older adults. Aging \& Mental Health. 2007; 11(5):496-504. [PubMed: 17882587]

Fries, JF. The Health Assessment Questionnaire. In: McDowell, I.; Newell, C., editors. Measuring health: A guide to rating scales and questionnaires. 2nd ed.. Oxford University Press; New York: 1996. p. 106-115.

Gruber VA, Wildman BG. The impact of dysmenorrheal on daily activities. Behavoir Research Therapy. 1987; 25(2):123-128.

Hawkley LC, Burleson MH, Berntson GG, Cacioppo JT. Loneliness in everyday life: Cardiovascular activity, psychosocial context, and health behaviors. Journal of Personality and Social Psychology. 2003; 85:105-120. [PubMed: 12872887]

Hawkley LC, Cacioppo JT. Loneliness matters: a theoretical and empirical review of consequences and mechanisms. Annals of Behavioral Medicine. 2010; 40(2):218-27. [PubMed: 20652462]

Hawkley L, Hughes M, Waite L, Masi C, Thisted R, Cacioppo J. From social structural factors to perceptions of relationship quality and loneliness: the Chicago Health, Aging, and Social Relations study. Journals of Gerontology Series B: Psychological Sciences \& Social Sciences. 2008; 63B(6):S375-84.

Heinrich LM, Gullone E. The clinical significance of loneliness: A literature Review. Clinical Psychology Review. 2006; 26(6):695-718. [PubMed: 16952717]

Hodgson N, Freedman VA, Granger DA, Emo A. Biobehavioral correlates of relocation in the frail elderly: Salivary cortisol, affect, and cognitive function. Journal of the American Geriatric Society. 2004; 52:1856-1862.

Killeen C. Loneliness: An epidemic in modern society. Journal of Advanced Nursing. 1998; 28(4): 762-770. [PubMed: 9829664]

Long MV, Martin P. Personality, relationship closeness, and loneliness of oldest old adults and their children. The Journals of Gerontology. 2000; 55B(5):311-319.

Lutgendorf SK, Reimer TT, Harvey JH, Marks G, Hong S, Let S, et al. Effects of housing relocation on immunocompetence and psychosocial functioning in older adults. Journals of Gerontology Series A: Biological Sciences and Medical Sciences. 2001; 56:M95-M105.

Mayers A, Svartberg M. Existential loneliness: A review of the concept, its psychosocial precipitants and psychotherapeutic implications for HIV-infected women. British Journal of Medical Psychology. 2001; 74(4):539-553. [PubMed: 11780800]

Mclnnis GJ, While JH. A phenomenological exploration of loneliness in the older Adults. Archives of Psychiatric Nursing. 2001; 15(3):128-139. [PubMed: 11413504] 
Mahon NE, Yarcheski A, Yarcheski TJ. Differences in social support and loneliness according to developmental stage and gender. Public Health Nursing. 1994; 11(5):361-368. [PubMed: 7971702]

McWhirter B. Loneliness: A review of current literature with implications for counseling and Research. Journal of Counseling and Development. 1990; 68(4):417-422.

Merck Institute of Aging \& Health. Centers for Disease Control and Prevention. Gerontological Society of America. The state of aging and health in America. 2004. Retrieved December 23, 2005, from http://www.cdc.gov/aging/pdf/State_of_Aging_and_Health_in_America_2004.pdf

Mijuskovic B. Loneliness and a theory of consciousness. Review of Existential Psychology and Psychiatry. 1977; 15(1):19-31.

Mullins LC, Elston CH, Gutkowski SM. Social determinants of loneliness among older Americans. Genetics, Social, \& General Psychology Monographs. 1996; 122(4):453-473.

Murphy, PM.; Kupshik, GA. Loneliness, stress and well-being: A helper's guide. Routledge; London: 1992.

National Center for Health Statistics. Health, United States health and aging chartbook. 1999. Retrieved November 15, 2005, from http://www.aspenpub.com/books/turnock/hus99cht.pdf

Nurmi J, Toivonen S, Salmela-Aro K, Eronen S. Social strategies and loneliness. Journal of Social Psychology. 1997; 137(6):764-778. [PubMed: 9414626]

Odell SH. Someone is lonely. Issues in Mental Health Nursing. 1981; 3(1-2):7-12. [PubMed: 6909157]

Pavri S. Loneliness in children with disabilities. Teaching Exceptional Children. 2001; 33(6):52-58.

Pinquart, M.; Sorensen, S. Risk factors for loneliness in adulthood and old age: A meta-analysis. In: Shohov, S., editor. Advances in Psychology Research. Vol. 19. Nova Science Publishers; Hauppauge, NY: 2003. p. 111-143.

Pfeiffer E. A Short Portable Mental Status Questionnaire for the assessment of organic brain deficit in elderly patients. Journal of the American Geriatric Society. 1975; 23:433-441.

Ponzetti JJ Jr. Loneliness among college students. Family Relations. 1990; 39(3):336-340.

Potter M, Zauszniewski J. Spirituality, resourcefulness, and arthritis impact on health perception of elders with rheumatoid arthritis. Journal of Holistic Nursing. 2000; 18(4):311-336. [PubMed: 11847790]

Radloff LS. The CES-D Scale: A self-report depression scale for research in The general population. Applied Psychological Measurement. 1977; 1:385-401.

Rice DP, Fineman N. Economic implications of increased longevity in the United States. Annual Review of Public Health. 2004; 25:1-17.

Rosedale M. Loneliness: An exploration of meaning. Journal of the American Psychiatric Nurses Association. 2007; 13(4):201-209.

Rosenbaum M. A schedule for assessing self-control behaviors: Preliminary findings. Behavior Therapy. 1980; 11:109-121.

Rosenbaum, M. Learned resourcefulness on coping skills, self-control, and adaptive behavior. Springer Publishing Company; New York: 1990.

Rook KS. Promoting social bonding: Strategies for helping the lonely and socially isolated. American Psychologist. 1984; 39(12):1389-1407.

Rush, AJ.; Beck, AT. Cognitive therapy. In: Kaplan, HI.; Sadock, BJ., editors. Comprehensive textbook of psychiatry. 7th ed.. Williams \& Wilkins; Baltimore: 2000.

Russell D. ULCA Loneliness Scale (version 3): Reliability, validity, and factor structure. Journal of Personality Assessment. 1996; 66(1):20-40. [PubMed: 8576833]

Seapersad, S. Applied interventions for loneliness. 2001-2010. Retrieved November 24, 2010 from http://www.webofloneliness.com/publications/critical/applied_intervention.htm

Spielberger, CD. Manual for the State-Trait Anxiety Inventory: STAI. Consulting Psychologists Press; Palo Alto, CA: 1983.

Stanley M, Novy D, Bourland S, Beck J, Averill P. Assessing older adults with generalized anxiety: a replication and extension. Behaviour Research and Therapy. 2001; 39(2):221-235. [PubMed: 11153975] 
Steptoe A, Owen N, Kunz-Ebrecht SR, Brydon L. Loneliness and neuroendocrine, cardiovascular, and inflammatory stress responses in middle-aged men and women. Psychoneuroendocinology. 2004; 29(5):593-611.

Stevens N. Combating loneliness: a friendship enrichment programme for older women. Aging and Society. 2001; 21:183-202.

Tiikkainen P, Heikkinen R. Associations between loneliness, depressive symptoms and perceived togetherness in older people. Aging \& Mental Health. 2005; 9(6):526-34. [PubMed: 16214700]

Winningham RG, Pike NL. A cognitive intervention to enhance institutionalized older adults' social support networks and decrease loneliness. Aging \& Mental Health. 2007; 11(6):716-721. [PubMed: 18074259]

Zauszniewski JA. Learned resourcefulness: A conceptual analysis. Issues in Mental Health Nursing. 1995; 16(1):13-31. [PubMed: 7706055]

Zauszniewski, JA. Resourcefulness: A new mid-range theory. In: Fitzpatrick, JJ.; Wallace, M., editors. Encyclopedia of Nursing Research. Springer Publishing; New York: 2006. p. 256-258.

Zauszniewski J, Bekhet A. Depressive symptoms in elderly women with chronic conditions: measurement issues. Aging \& Mental Health. 2009; 13(1):64-72. [PubMed: 19197691]

Zauszniewski J, Eggenschwiler K, Preechawong S, Roberts B, Morris D. Effects of teaching resourcefulness skills to elders. Aging \& Mental Health. 2006; 10(4):404-412. [PubMed: 16798633]

Zauszniewski J, Graham G. Comparison of short scales to measure depressive symptoms in elders with diabetes. Western Journal of Nursing Research. 2009; 31(2):219-234. [PubMed: 19050228]

Zauszniewski J, Morris D, Preechawong S, Chang H. Reports on depressive symptoms in older adults with chronic conditions. Research and Theory for Nursing Practice. 2004; 18(2-3):185-196.

[PubMed: 15553346] 


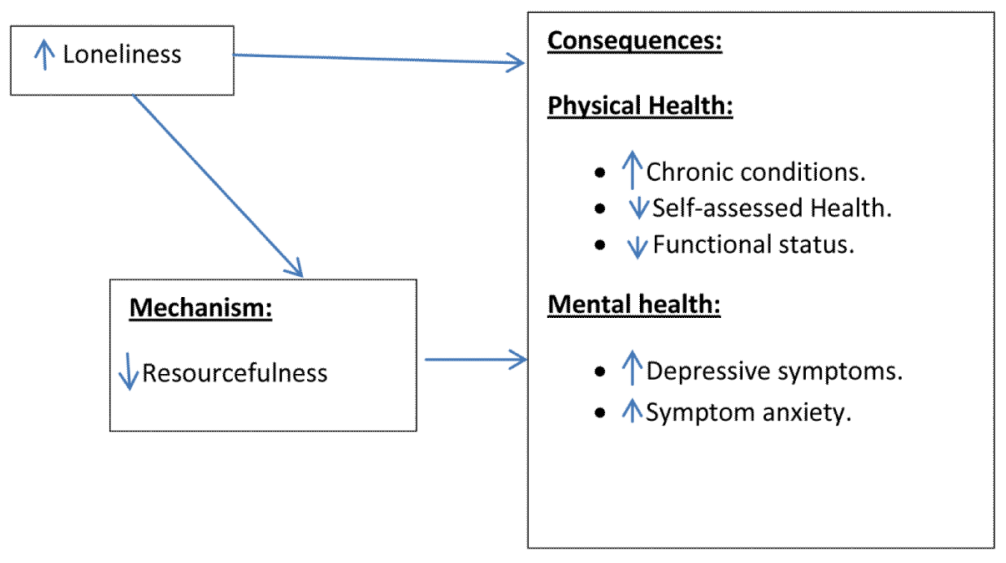

Figure 1.

Theoretical framework showing potential effects (mechanism and consequences) of loneliness. 


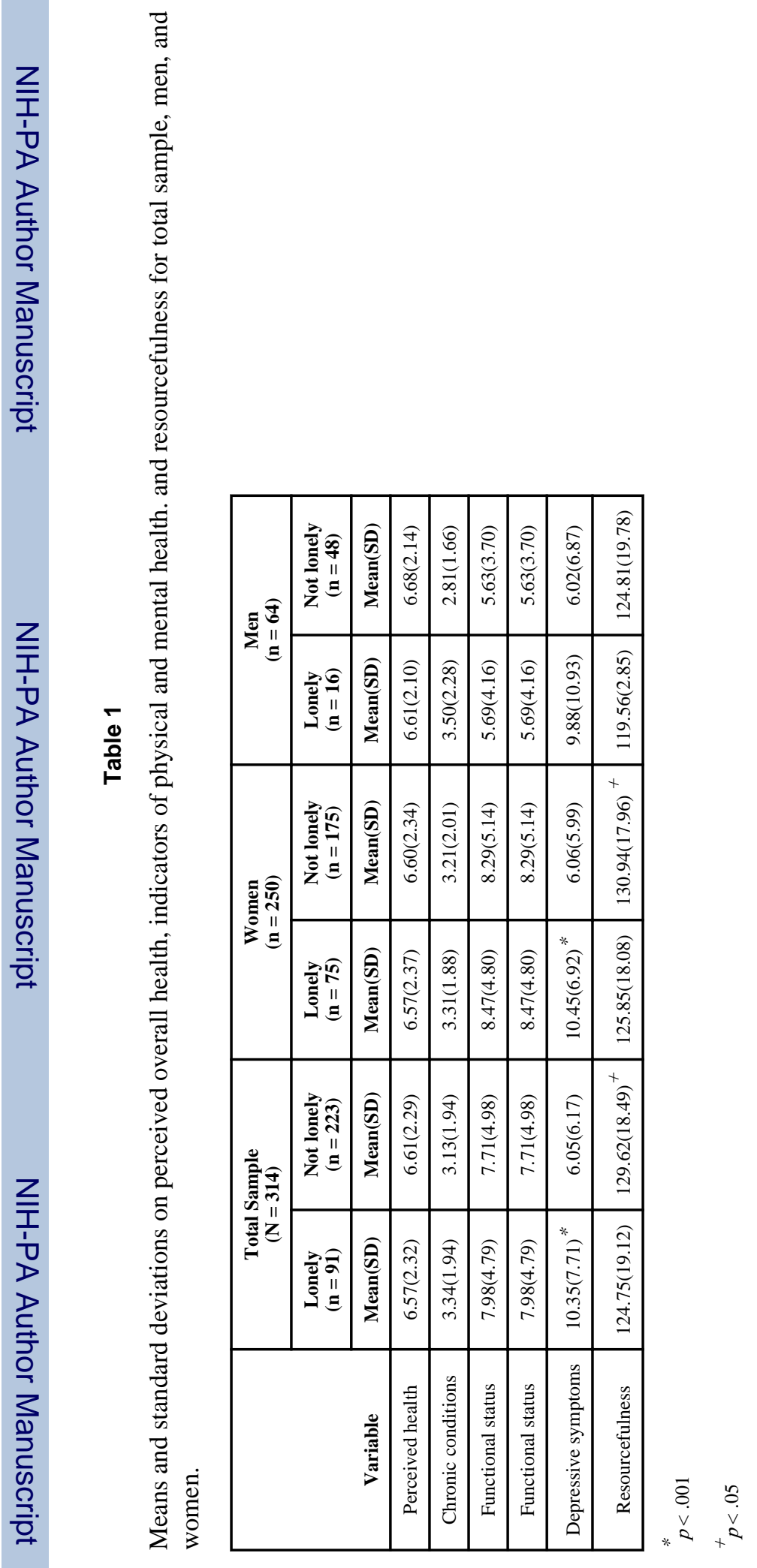

